\title{
Verification of Building Constructions Surroundings Based on Airborne Laser Scanning Data
}

\author{
Maja Michałowska \\ University of Warmia and Mazury in Olsztyn, Institute of Geodesy, ul. Oczapowskiego 1, \\ 10-719 Olsztyn, Poland, maja.michalowska@uwm.edu.pl
}

\begin{abstract}
Light Detection and Ranging, as an active Remote Sensing Technology, enables gathering accurate, three-dimensional point cloud of scanned objects. Laser scanning might be provided on the terrestrial level for specific, defined constructions, as well as on the airborne level for aerial or linear objects. Using a laser sensor mounted on a moving platform is currently the most efficient way of obtaining in a short period, accurate positions of billions of points as a representation of a scanned area. Based on this kind of dataset it is possible to perform three-dimensional analysis of the safety of scanned objects without additional measurements in the field. This article presents the analysis performed in vMatic software on data from Airborne Laser Scanning for medium voltage power line verification of obstacles with the buildings. The analysis took less than 20 seconds for the detection of buildings points that are closer than $5 \mathrm{~m}$ from conductors for seven spans wit a total length of almost $400 \mathrm{~m}$. Providing distance verification on $3 D$ point cloud data is the fastest way to obtain a hazard awareness in a short time. Once acquired by LiDAR data can be used for other various analyses for any construction, depending on current, expected and future needs.
\end{abstract}

Keywords: Point Cloud, Laser Scanning, LiDAR, ALS, Remote Sensing, 3D Analysis, Hazards, Obstacles, Collisions, Power Lines.

\section{Introduction}

Laser scanning is the most popular technology that enables obtaining accurate, threedimensional point cloud of scanned objects in a short time. Scanning might be provided on the terrestrial level (Terrestrial Laser Scanning - TLS) for construction like architectural heritage (Pritchard et al., 2017), buildings (Karagianni, 2017), bridges (Truong-Hong and Laefer, 2015), and on the airborne level (Airborne Laser Scanning - ALS) using flying platform (airplane, helicopter, unmanned aerial vehicle - UAV), for aerial objects like forests (Hyyppä et al., 2012), environmental heritage, as well as for linear objects: power lines (Kwoczyńska and Dobek, 2016), roads, railways (Zhu and Hyyppä, 2014), etc.

Using a multi-sensors mounted on a moving platform, as a Mobile Mapping Technology (MMT), is currently the most efficient way of obtaining in a short time, accurate positions of billions of points as a representation of a scanned area (Tao and Li, 2020). MMT is using mostly in projects for aerial and linear objects reachable from a path of the mobile platform. Choosing a type of platform that carrying all technical equipment, have to be adjusted to the kind of object that have to be scanned and the purpose of the scanning. Using a car, as a mobile platform, for power line corridor scanning while there are no roads near the power lines, is not a good idea it would be more propriety to choose a helicopter or a plane for this purpose. It has to be noticed that Airborne Mobile Mapping using airplanes or helicopters is much more expensive than using Terrestrial Mobile Mapping with a car as a moving platform. 


\subsection{Mobile Airborne Laser Scanning system}

Mobile Mapping Systems (MMS) used in the ALS technique consist of among others laser scanner, Global Positioning System (GPS) receiver and Inertial Measurement Unit (IMU). The principle of the laser sensor is to release a pulse of infrared or near-infrared light, capture returned pulses and record the length of time the pulse reaches an object and is reflected to the sensor. Based on the recorded information distance to the reflected point from a laser scanner can be calculated. It's essential to record by GPS receiver using Global Navigation Satellite System (GNSS) a position of the flying platform and parallelly precise orientation of the laser scanner by IMU. This information is the key to calculate a highly accurate position in $3 \mathrm{D}$ dimensions of the laser scanner and all measured by scanner points during the acquisition.

\section{Materials and Methods}

\subsection{Field Data}

Vimap company, that provides MMT services for the energy sector, provided for research purposes a sample of a point cloud data acquired by Airborne Laser Scanning. Data was acquired in 2016, in Poland, near Ostróda city, for the MV power line corridor, as a test data for test flights before launching a commercial power lines ALS project. The sample test flight was done for about $400 \mathrm{~m}$ of power line in an urban area, which includes seven spans, from pole with a number of 14 to pole with a number of 19

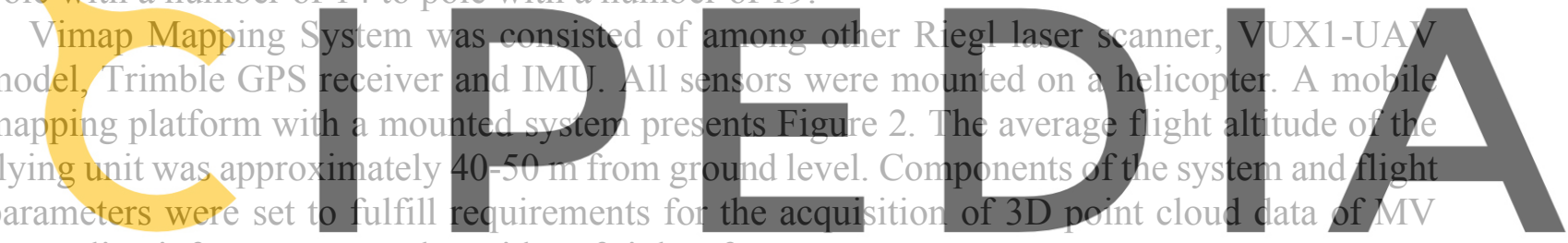
power line infrastructure and corridor of right-of-way.

Register for free at https//www.scipedia.com to download the version without the watermark

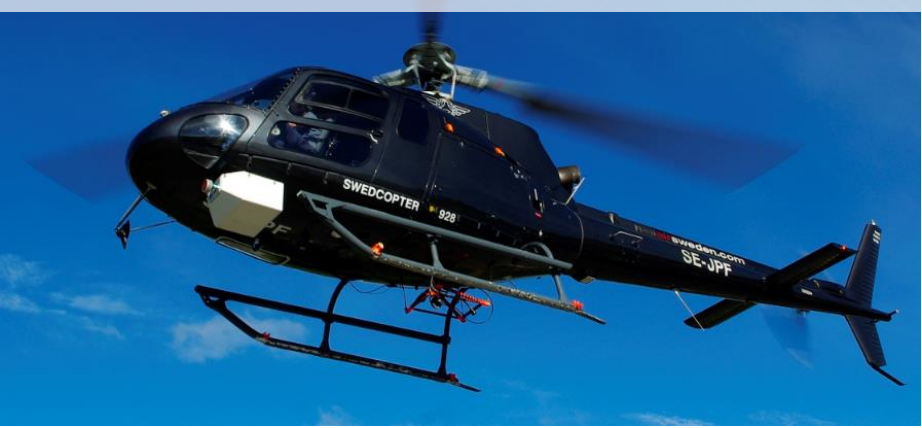

Figure 2. Mobile platform with the measuring system.

Laser scanner that was used in the measuring system, Riegl VUX1-UAV, is dedicated to agriculture, forestry, archaeology, cultural heritage documentation, as well as corridor mapping for power lines, railway tracks, pipeline inspection, topography in open-cast mining and other. 
Figure 3 presents Riegl VUX1-UAV laser scanner used in Airborne Laser Scanning (source: http://www.riegl.com/products/unmanned-scanning/riegl-vux-1uav/, 2020-04-13).

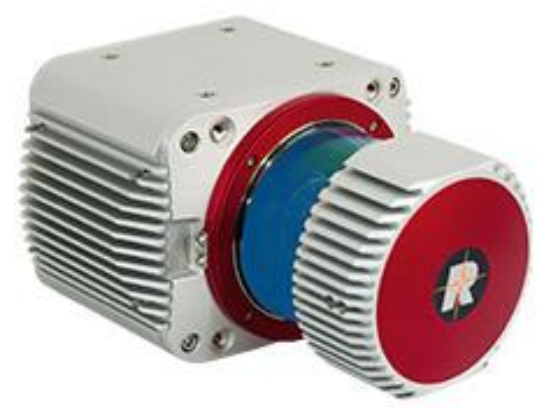

Figure 3. Laser scanner model used in ALS.

Technical parameters of the laser scanner, altitude and speed of the helicopter flight allow achievement of the density of 40 points per square meter. The technical specification of the laser seanner used in the Airborne Mobile Mapping System presents Table 1.

Table 1. Technical specification of the laser scanner used in the Airborne Mobile Mapping System.
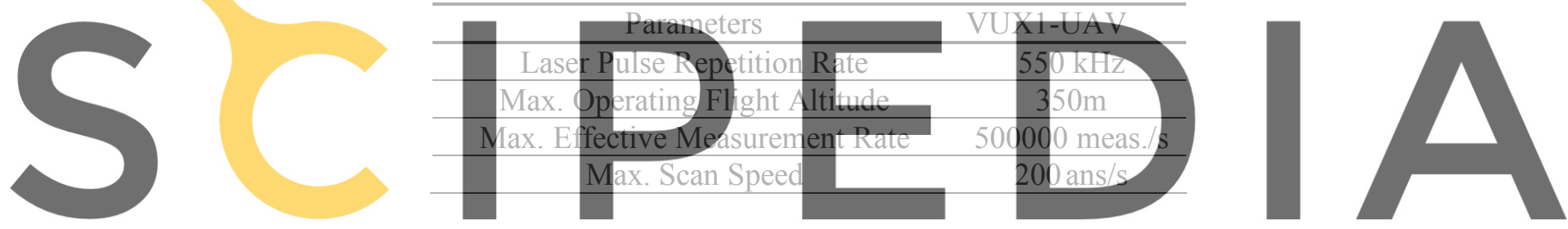

\subsection{Point Cloud Data Elaboration}

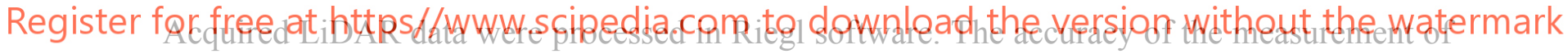

horizontal coordinates $(\mathrm{X}, \mathrm{Y}) \mathrm{RMSE}=0.05 \mathrm{~m}$, accuracy of point height measurement $(\mathrm{Z})$ RiviSE $=0.10 \mathrm{~m}$. The point cloud density equais $55 \mathrm{pts} / \mathrm{m}^{2}$.

As the main reason for the Airborne Laser Scanning of MV power lines was to provide 3D analysis of the surroundings of the power line, two basic processes were needed - classification and power line modeling. In those steps, data was elaborated in TerraSoild and Microstation software.

\subsubsection{Classification}

Classifying of the LiDAR data into categorical object instances is the most critical step for further 3D analysis and modeling. It's a process of assigning a label to the points that represent a specified object, like the ground, building construction, power lines infrastructure, vegetation, etc. Classification allows us to group bunches of points into the specified representative of an object class, which helps to provide further $3 \mathrm{D}$ analysis. The correctness of classification has a big impact on the results of analyses that might be performed on classified data. Figure 4 presents a point cloud acquired by a laser scanner, as an input data for the classification process. Figure 5 presents the point cloud after classification. 


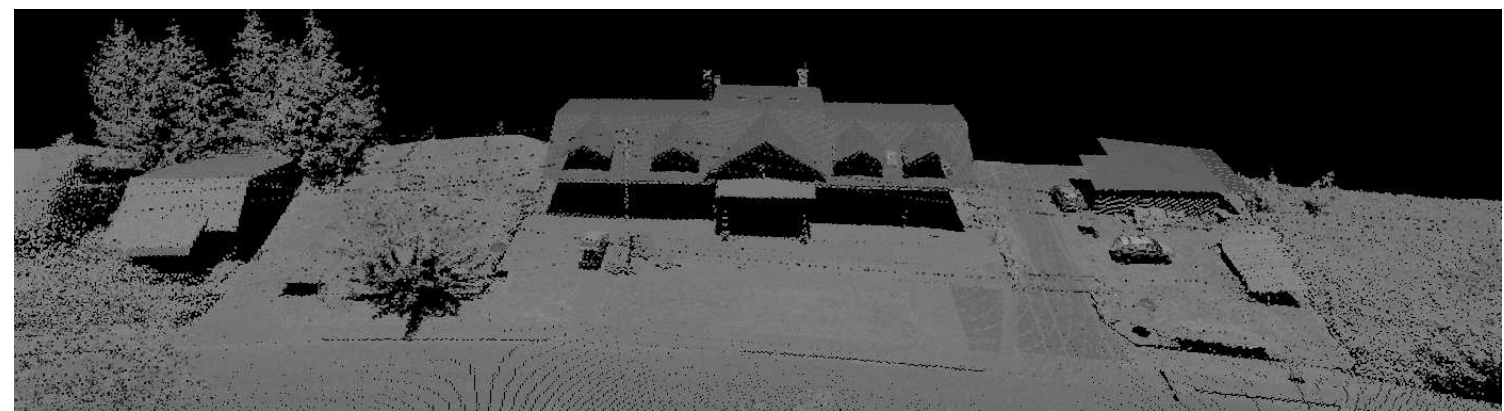

Figure 4. Point cloud with no classification - color by point intensity.

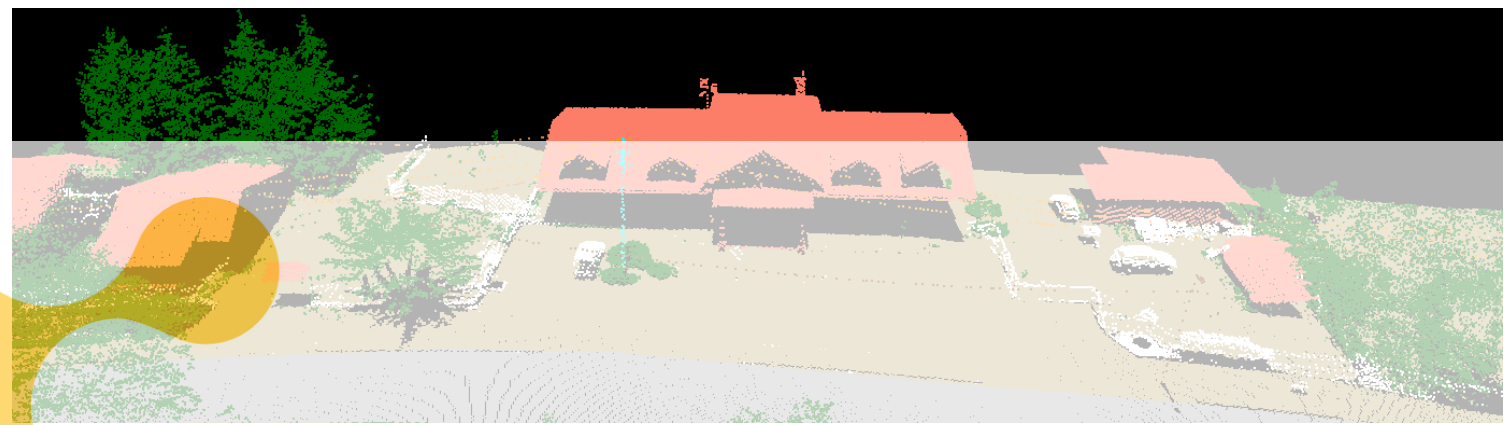

Figure 5. Point cloud with classification.

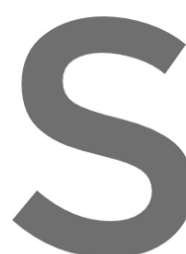

Sample of acquired LiDAR data was classified semi-auton
segment-based classification strategy and manual corrections
There were extracted objects of following classes: ground, bu
wires, power line pylons pipeline, paved road, unpaved road, wat

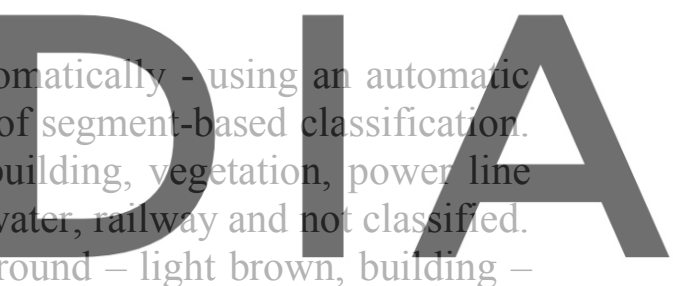

Figure 5 presents classified objects in the following colors: ground - light brown, building red, vegetation - green, power line wires - yellow, power line pylons - blue, paved road - gray,

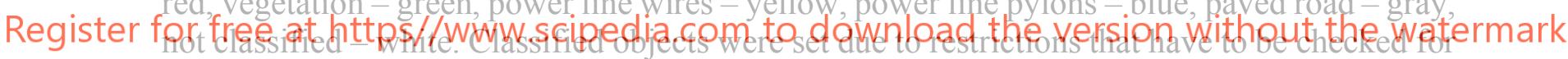

a power line infrastructure on the point cloud data.

\subsubsection{Objects Modeling}

Poles and phase cables of the MV power line were digitized based on the point cloud and save to 3D ESRI shapefile. Visualization of the digitized 3D model in Google Earth Pro is presented in Figure 6.

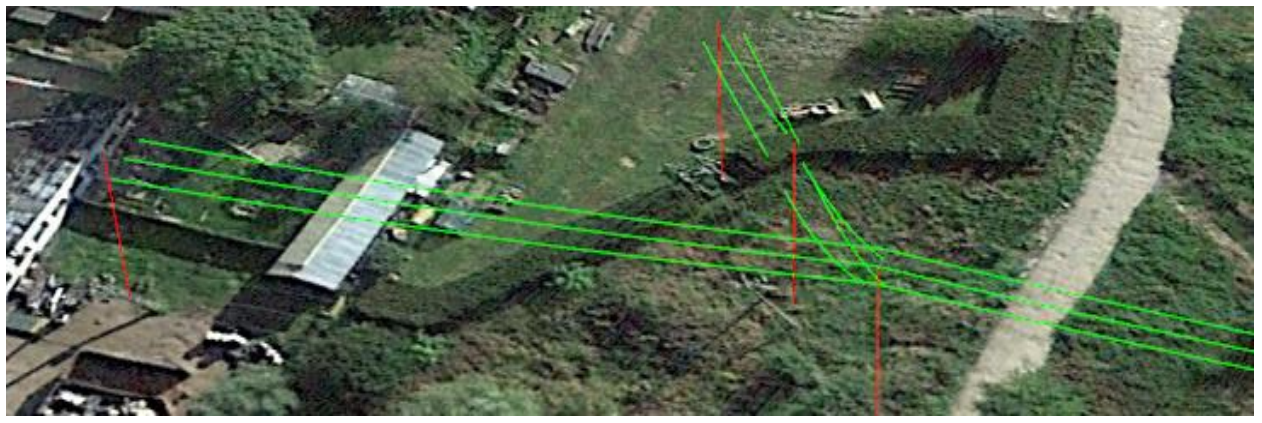

Figure 6. Visualization of the digitized 3D model in Google Earth Pro. 


\section{3 vMatic Software}

vMatic software, developed by Vimap company, enables point cloud presentation and automatic performance of three-dimensional analysis based on digitized 3D models. The user interface of vMatic software and visualization of point cloud and 3D model presents Figure 7.

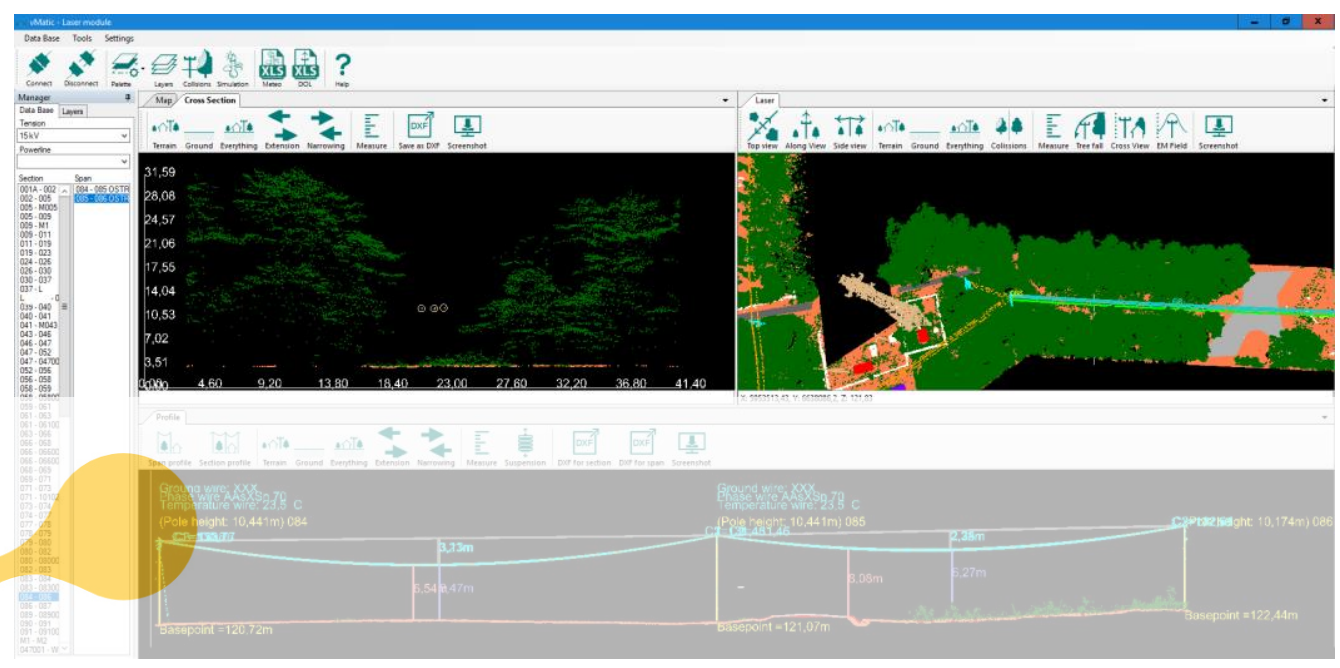

Figure 7. vMatic software - visualization of ALS data.

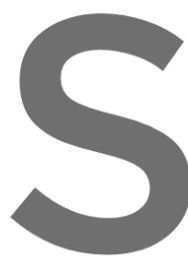

\section{vMatic software was} from power lines to near power line. The analysis line, as well as at simula Classified LiD AR dat basic inputs for 3D analysis in r
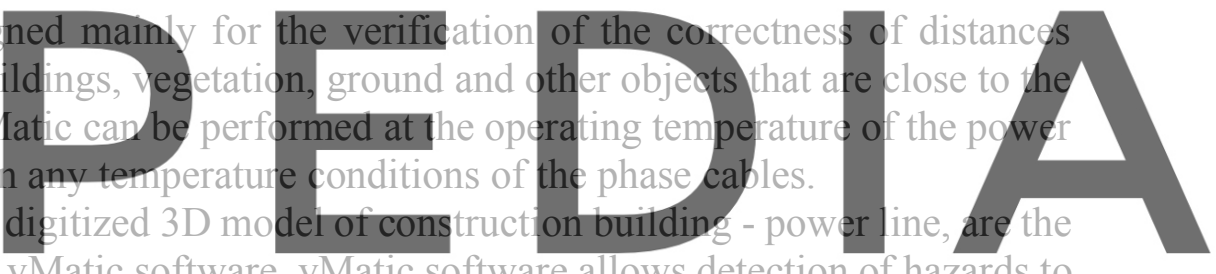
cylinder with a radius specifled by the user, along the course or the 3D model object and thermark detecting whether the cylinder encounters points of the particular class.

\section{Results}

Based on acquired ALS data of the middle voltage power line corridor in an urban area, the detection of collisions with buildings was performed for digitized phase cables of the line for seven spans, from 14th pole to 19th pole (total length: $367 \mathrm{~m}$ ). Figure 8 shows the analyzed area on an orthophotomap, poles positions with their numbers are presented in yellow color. 


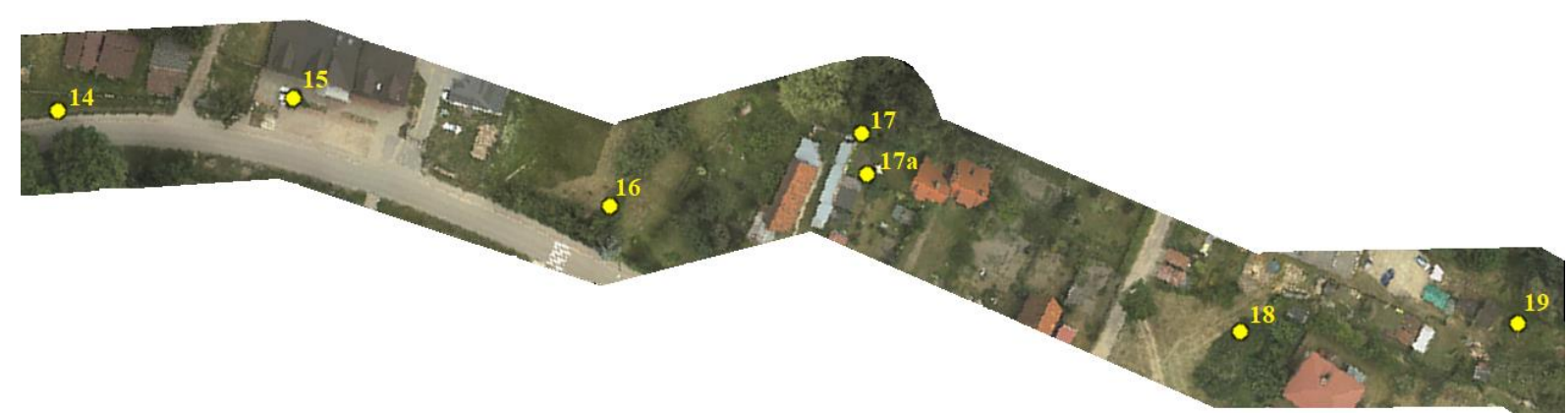

Figure 8. Analyzed the MV power line corridor in the urban area.

The radius of a virtual cylinder was set at $5 \mathrm{~m}$. It means, that from each digitized phase cable detection of buildings point will be done in $5 \mathrm{~m}$ distance and $360^{\circ}$ range along the course of the conductor. The collision analysis for seven spans took 19 seconds in vMatic software.

Tool for automatic detection of building collision in 5m 3D range buffer from the power line conductors found in total 9 building obstacles. Two buildings were in a really close area to the power line, with the closest $3 \mathrm{D}$ distance equals $2.64 \mathrm{~m}$ (span from $16^{\text {th }}$ pole to $17^{\text {th }}$ pole) and $2.77 \mathrm{~m}$ (span from $17^{\text {th }}$ a pole to $18^{\text {th }}$ pole). One building was detected in $3.00-3.99 \mathrm{~m}$ collision range, six buildings in a range from $4.00 \mathrm{~m}$ to $5.00 \mathrm{~m}$. The other fifteen buildings in the analyzed area weren't found due to 3D distance from power line wires to the building bigger than $5 \mathrm{~m}$. The results of the performed analysis with division into ranges of a 3D collision distance shows

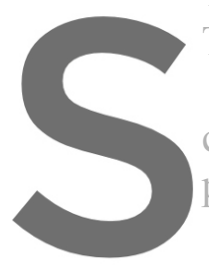
Table 2.

Figure 10 presents the collision colors presente presented in light green
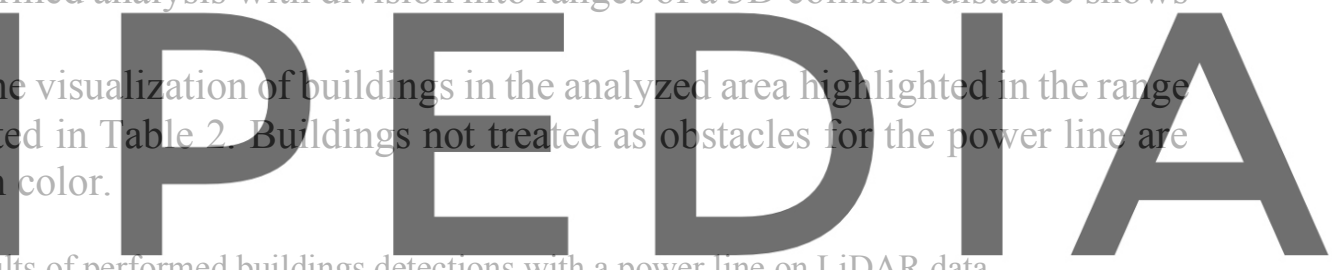

Table 2. Results of performed buildings detections with a power line on LiDAR data.

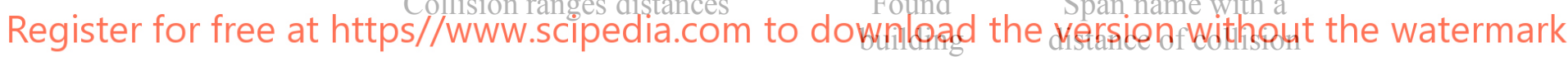

\begin{tabular}{rrr} 
& collision & \\
\hline & 0 & - \\
\hline $2.00 \mathrm{~m}-2.99 \mathrm{~m}$ & 2 & $16-172.64 \mathrm{~m}$ \\
& & $17 \mathrm{a}-182.77 \mathrm{~m}$ \\
\hline $3.00 \mathrm{~m}-3.99 \mathrm{~m}$ & 1 & $18-163.85 \mathrm{~m}$ \\
\hline $4.00 \mathrm{~m}-4.49 \mathrm{~m}$ & 2 & $18-194.12 \mathrm{~m}$ \\
& & $17 \mathrm{a}-184.56 \mathrm{~m}$ \\
\hline $4.50 \mathrm{~m}-5.00 \mathrm{~m}$ & 4 & $15-164.81 \mathrm{~m}$ \\
& & $15-164.84 \mathrm{~m}$ \\
& & $18-194.97 \mathrm{~m}$ \\
\hline
\end{tabular}




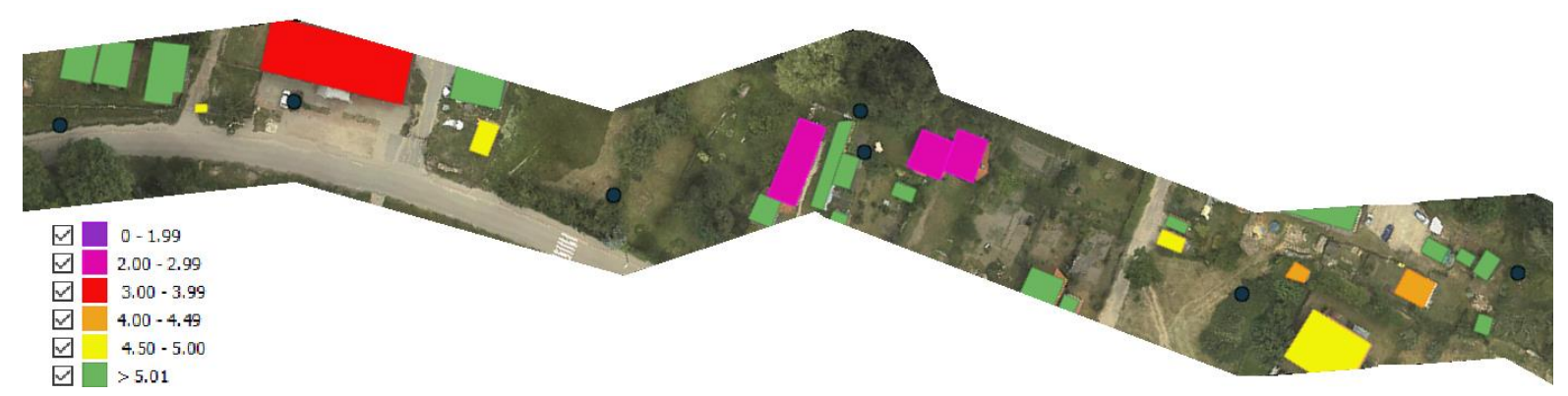

Figure 10. Buildings colored by a collision distance to the power line.

Figure 9 presents in vMatic software visualization of the closest collision from the power line wires to the building point with a distance of $2.64 \mathrm{~m}$ (span from nole $16^{\text {th }}$ to $17^{\text {th }}$ ). The point cloud is visualized in RGB colors, the area of collision of building points closer than $5 \mathrm{~m}$ from power line wires is highlighted in red color.
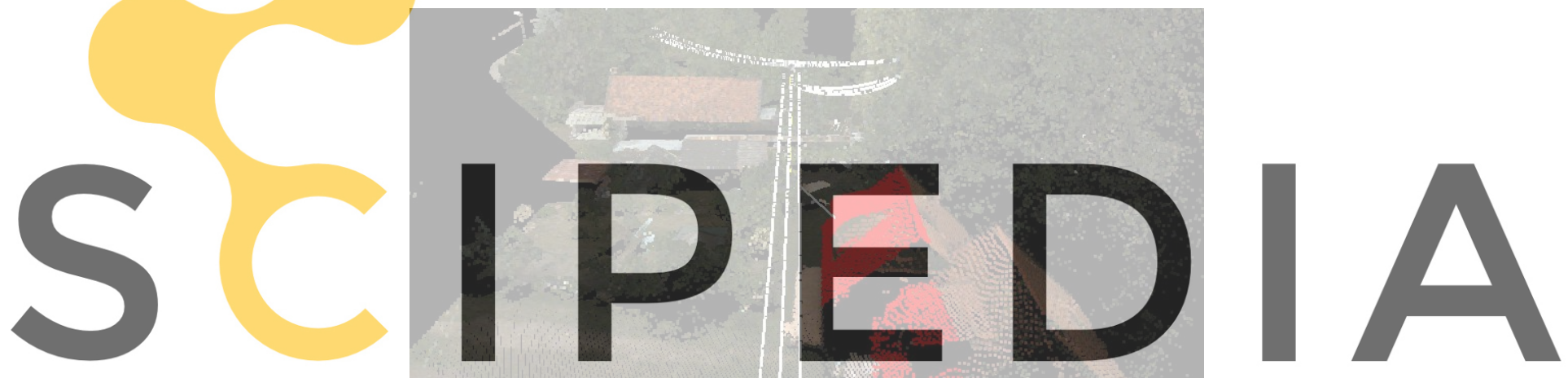

\section{Register for free at https//www.scipedia.com to download the version without the watermark}

Figure 9. Found building close-up to the power line in vMatic software.

\section{Conclusions}

LiDAR data allows the performance of three-dimensional analysis for building constructions without any additional measurements in the field. Based on data gathered by remote sensing technology, verification of any construction surroundings can be performed in dedicated software to ensure the safety of the objects.

Performed in this article analysis of the power line obstacles were detected in vMatic software. The analysis took less than 20 seconds for the detection of buildings points (closer than $5 \mathrm{~m}$ from conductors) for almost $400 \mathrm{~m}$ length of the MV power line. vMatic software detected nine buildings that are too close to the power line.

Data from laser scanning, as a true representative of scanned objects/areas, might become a basic, complete product for providing 2D and $3 \mathrm{D}$ analysis. The results of the analysis performed on LiDAR data are reliable. Providing distance verification on 3D point cloud data is the fastest way to obtain a hazard awareness in a short time. Once acquired by LiDAR data can be used 
for other various analyses for any construction, depending on current, expected and future needs.

\section{ORCID}

Maja Michałowska: http://orcid.org/0000-0002-5321-7946

\section{References}

Hyyppä, J., Yu X., Hyyppä, H., Vastaranta, M., Holopainen, M., Kukko, A., Kaartinen, H., Jaakkola, A., Vaaja, M. and Koskinen, J. (2012). Advances in Forest Inventory Using Airborne Laser Scanning. Remote Sensing 4 (1 December 2012), 1190-1207.

Karagianni, A. (2017). Terrestrial Laser Scanning in Building Documentation. Civil Engineering and Architecture $5.6(2017) 215-221$.

Kwoczyńska, B. and Dobek, J. (2016). Elaboration of the $3 d$ Model and Survey of the Power Lines Using Data from Airborne Laser Scanning, Journal of Ecological Engineering 17 (1 September 2016): 65-74.

Pritchard, D., Sperner, J. Hocpner, S. and Tenschert, R., (2017). Terrestrial Laser Scanning for Heritage Conservation: The Cologne Cathedral Documentation Project, IV-2/W2:213-20.

Tao, V. C. and Li, J. (2020). Advances in Mobile Mapping Technology, 5 February 2020, Advances in Mobile Mapping Technology: ISPRS Series, volume 4.

Truong-Hong, L. and Laefer, D. F. (2015). Documentation of Bridges by Terrestrial Laser Scanner, IABSE Symposium Report, 105(19), 1-8.

Zhu, L. and Hyyppä, J. (2014). The Use of Airborne and Mobile Laser Scanning for Modeling Railway Environments in 3D, Remote Sensing 6 (4 April 2014): 3075-3100.

http://www.riegl.com/products/unmanned-scanning/riegl-vux-1uav/ 2020-04-13
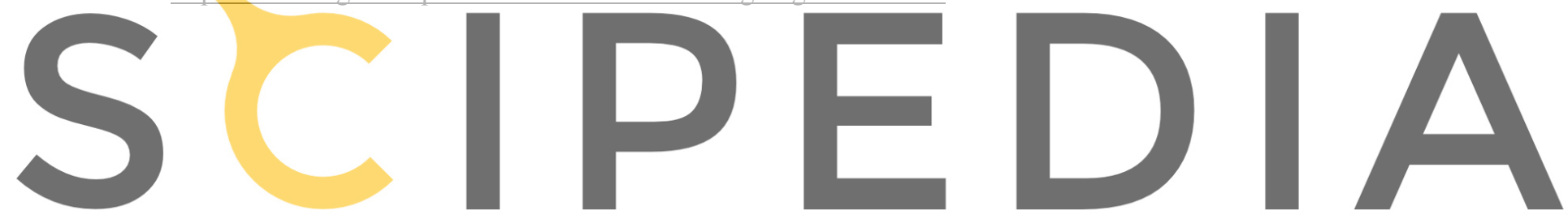

Register for free at https//www.scipedia.com to download the version without the watermark 